\title{
A Novel Device to Monitor Bottom Soil of Water Basin Using Ultrasound Technology
}

\author{
NAKAO NOMURA', YUJI SUGIURA², MASAHIRO TOYODA², KEIICHI SATO², \\ YASUHIRO YAGITA ${ }^{2}$, KAZUNORI NAKANO ${ }^{3}$, YUHEI INAMORI ${ }^{4}$, \\ and MASATOSHI MATSUMURA ${ }^{3}$
}

\author{
${ }^{1}$ Science and Technology Promotion Foundation of Ibaraki/ Tsukuba, Ibaraki, Japan \\ ${ }^{2}$ Honda Electronics Co. Ltd, Aichi, Japan/ 20 Koyamatsuka, Toyohashi, Aichi, Japan \\ ${ }^{3}$ Institute of Applied Biochemistry, University of Tsukuba/1-1-1 Tennodai, Tsukuba, Ibaraki, Japan \\ ${ }^{4}$ National Institute of Environmental Studies/16-2 Onogawa, Tsukuba, Ibaraki, Japan
}

\begin{abstract}
Sediment monitoring device using ultrasound was constructed. Location data of the monitoring position was identified by coupling with global positioning system. It was found that ultrasound at $\mathbf{4 0} \mathrm{kHz}$ frequency was optimum for scanning the lake and bay sediments layer. Comparison between scanning results using ultrasound and chemical analysis revealed that there is a correlation between organic matter contents in the soil and scanning data.
\end{abstract}

Keywords: ultrasound, sediment scanning, particle analysis, organic matter, global positioning system

\section{INTRODUCTION}

Pollution of lakes and coastal environments is caused not only through inputs by river water flow but also by influences of bottom soil ${ }^{1)}$. It seems that development of technologies for sediment quality improvement is relatively delayed compared with those for water quality improvement. This has resulted to the fact that treatment of sediment in lakes or coasts have been conducted by dredging as tentative countermeasure.

One of the problems for sediment treatment is to assess how much sediment quality has been deteriorated and where the polluted sediment is located. Primarily, most polluted portion of the bottom soil is usually the surface sediment which is up to the $10 \mathrm{~cm}$ depth. However, the surface of sediments is usually turbid or of soft mud that is highly watery. Therefore, it is difficult to take sediment sample in exactly the same conditions as it was in natural environments.
There have been some attempts to develop a new device for collecting sediment samples. A core sampler for soft sediment in shallow water was developed by John et $a l^{2}$. Some sensors can be attached with the core sampler. In situ freezing of samples has been applied for sediment core $^{3)}$. Some devices were also developed for collecting the bottom water or pore water in the sediment ${ }^{4-6)}$. Frank et al. modified analytical methods for sediment core sample to minimize the redistribution of organisms ${ }^{7}$. Their modification was effective in collecting the sediment core sample with microorganisms as in natural environment.

Devices and prototypes which are cited above need direct collection of the sediment samples and samples have to be transported to the laboratories where detailed analysis has to be conducted. This is time-consuming and sometimes causes inaccuracy of data. It is desirable to monitor the sediment quality in the field without direct sampling.

Ultrasound technology has been widely 
applied for fish finder or fetus analyzer because of high resolution in detecting the object in the liquid phase. Ultrasound technology is also used to detect the depth of water layer in treatment tanks of wastewaters. This is in order to monitor scum accumulation coming from excess the activated sludge at the bottom, and also in determining the correct timing for sludge recovery from bottom of the tank. This implies that ultrasound can be used to detect the sediment bottom consisting of very soft substances like activated sludge, which has very similar texture with polluted lakes or sea sediments with high organic matter.

In this work, ultrasound technology was applied for monitoring sediment quality, and a prototype for monitoring unit including global positioning system for locating monitoring position was constructed. The prototype was tested in the field and results obtained from prototype were compared with the results of physicochemical analysis of sample from same sediments obtained using a sediment core sampler.

\section{MATERIALS AND METHODS}

Sediment monitoring device The sediment monitoring device was composed of transducer and receiver for transfer of echo (Honda Electoronics), global positioning system, personal computer (Toshiba) and main unit with data processor (Fig.1). The field test run of the unit was conducted in the Mikawa Bay in Aichi prefecture and

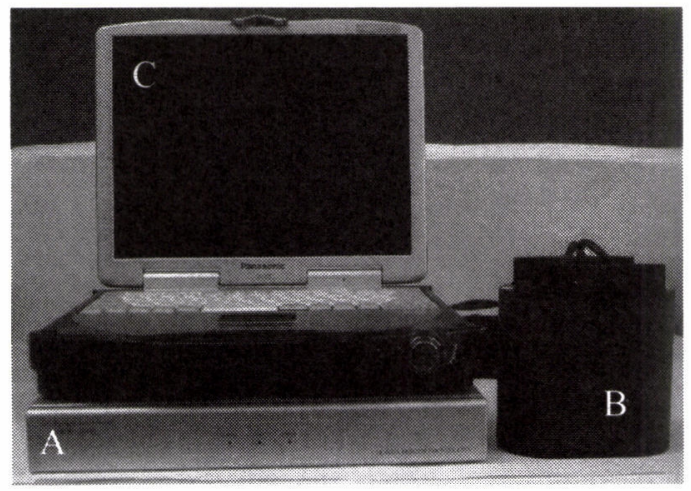

Fig. 1 Main components of sediment scanning device $\mathrm{A}$ : main unit, $\mathrm{B}$ : transducer and receiver $\mathrm{C}$ : personal computer
Takahama-oki area of Lake Kasumigaura in Ibaraki Prefecture, Japan in December 2001.

Sampling of sediment core and analysis of sediment chemical properties Sediment core samples were collected by using a core sampler (Daiki). Ekman-Birge type bottom sampler (Rigo) was used for taking samples from different types of soil. Particle size, density and soil chemical analysis were conducted by using methods reported previously.

\section{RESULTS AND DISCUSSION}

Construction of the fundamental structure for sediment monitoring device To establish the monitoring device for real time information of sediment quality and location in the field, a system as shown in Fig.2 was constructed. Information from sediment was sent to laptop computer through ultrasound controller. At the same time, location data from GPS was sent to laptop computer. Both data were combined and displayed as illustrated in Fig.3. First of all, frequency of ultrasound was optimized for sediment scanning by using sediment from Lake Kasumigaura. It was found that $40 \mathrm{kHz}$ is the most suitable for scanning the lake sediment with high pollution. The colors of the dots illustrate the difference in the properties in terms of hardness or density. The dots colored green or blue illustrate substance consisting of materials with softer texture or lower density and red-colored dots illustrate substance consisting of materials with harder texture or higher density. As shown in Fig.3, reflection of the echo from sediment was able to show the texture of the sediment. The layer which consisted of soft mud at the surface of bottom soil was able to be clearly differentiated from rigid earth layer. In this way, accumulation of soft layer in the rigid earth can be detected by the sediment scanning device.

Comparison of the results between data obtained from ultrasound and chemical analysis of sediment core sample Figure 4 shows comparison between particle analysis of sediment core sample and data obtained from sediment scanning by ultrasound. There was no clear correlation between the two data. There may be two reasons, for this 
observations. One is that scanning by ultrasound cannot tell the difference in particle composition of the sediment. Another is that there is a difficulty in taking the sediment core sample as same condition as in natural environment. It is known that highly watery sediment has more difficulty for sampling ${ }^{3)}$ and the sediment in the sampling site (Mikawa Bay area) was very soft and watery.

Figure 5 shows comparison between organic matter content of sediment core sample and the data obtained from sediment scanning by ultrasound. As can be seen at the depth of $35 \mathrm{~cm}$, there was a distinct decrease of organic matter content. The results of sediment scanning also show clear difference at the depth of $35 \mathrm{~cm}$ showing that there was change in sediment property. It is thought that the change in organic matter is due to

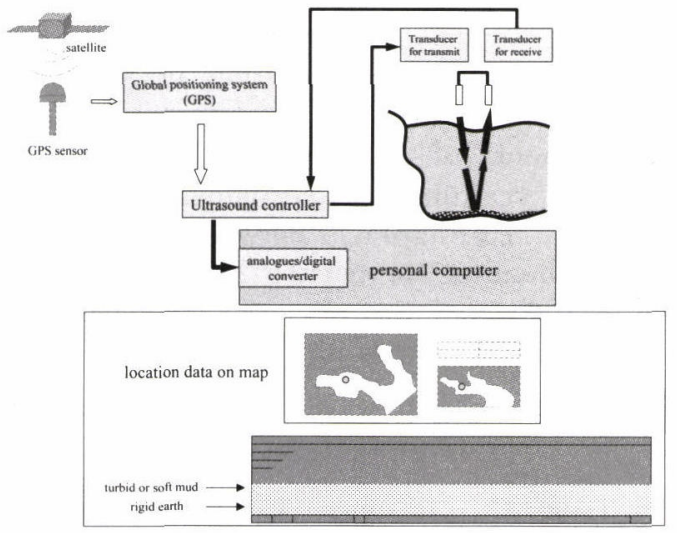

Fig. 2 Schematic diagram of the sediment scanning device
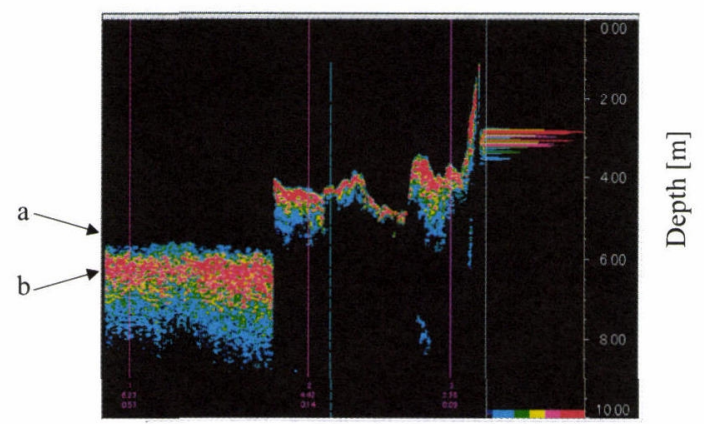

Fig. 3 Results of sediment scanning by ultrasound a: turbid layer, b: rigid earth the high particle density. The high particle density was detected by ultrasound scanning and shown as red-colored dots in Fig.3. At the depth of $35 \mathrm{~cm}$, particle density was lower than other depths resulting in the low organic matter, and this low particle density was scanned by ultrasound and were shown as green-colored dots in Fig.5.

Ultrasound scanning of the different types of sediments Different types of sediments were monitored using ultrasound. Samples were taken from Takahama-oki area in Lake Kasumigaura. Figure 6 shows the results of the comparison of scanning different types of sediment. It was found by eye observation that among 4 sampling points, samples from

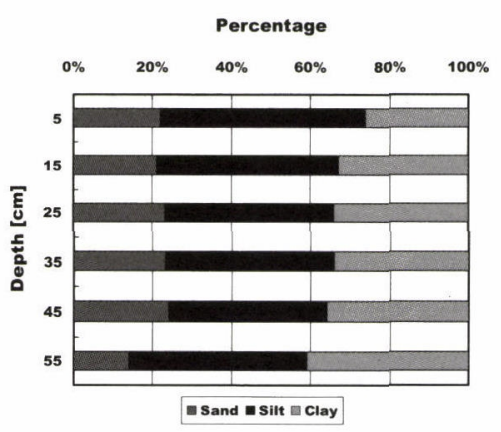

a

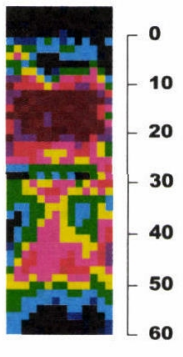

b
Fig. 4 Comparison between particle analysis of sediment core sample and data obtained from sediment scanning by ultrasound

a: particle analysis of sediment core sample

b: scanned image by using ultrasound

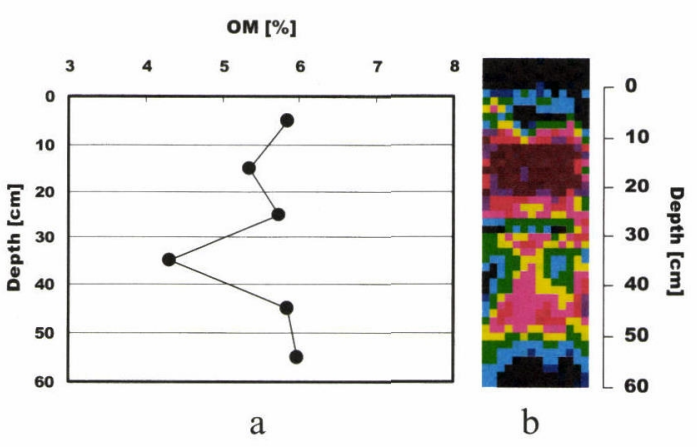

Fig. 5 Comparison between organic matter content of sediment core sample and data obtained from sediment scanning by ultrasound

a: particle analysis of sediment core sample

b: scanned image by using ultrasound 

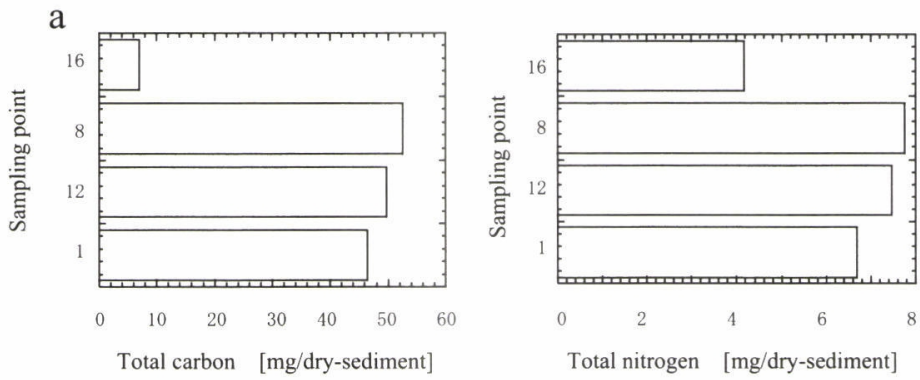

b

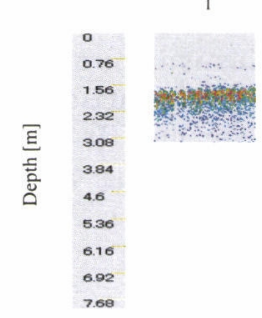

12

8

16

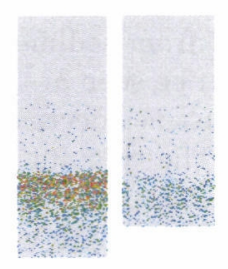

Fig. 6 Comparison of chemical analysis (a) and sediment monitoring using ultrasound (b) of the sediment from different portion of Lake Kasumigaura

sampling point 1,8 , and 12 were clay-like soil consisting of very fine soil particles, while sample from sampling point 16 was obviously sandy soil consisting of relatively rough soil particles. This was confirmed as the difference in carbon and nitrogen contents as shown in Fig. 6-a. Results of monitoring using ultrasound are shown in Fig. 6-b. In the Figure, the scanning data of sample from 6 was clearly different from other samples. It can be said that the blue or green dots detected in the data from sample 6 are not due to the soft texture of the sediment, but rather due to the fact that. echo from the device was almost absorbed, and reflection from the sediment was weak because sandy soils have more pore spaces between soil particles than clay-like soils. Nevertheless, it was found that sandy and clay-like soils were clearly differentiated using ultrasound.

\section{CONCLUSIONS}

From this study, ultrasound was applied to monitor bottom sediments and it was found that differences in organic matter content in the sediment was detected by ultrasound scanning. The organic matter content of the sediment is also one of the important criteria for sediment eutrophication. Therefore, using ultrasound technique, location of sediment eutrophication can be measured. For the development of useful and conventional sediment scanning device using ultrasound, detailed correlation between sediment physicochemical properties including some more additional parameters and sediment scanning by ultrasound is now being undertaken.

\section{REFFERENCE}

1) Tada C., Itayama T., Nishimura O., Inamori Y., Sugiura N., and Matsumura M.: The effect of manganese released from lake sediment on the growth of cyanobacterium Microcystis aeruginosa, J. Journal of Water Treatment Biology, 38(2), 95-102 (2002)

2 ) John R Meriwether et al:: Coring Sampler for Chemical Analysis of Soft Sediments, Microchemical Journal, 53, 201-206 (1996)

3 ) A. F. Lotter et al.: A remote controlled freeze corer for sampling unconsolidated surface sediments, Aquat. Sci., 59, 295303 (1997)

4 ) Andrea Bertolin et al.: A new device for in situ pore water sampling, Marine Chemistry, 49, 233-239 (1995) 
5 ) Allen Reed et al.: An inexpensive bottom water sampler, Continental Shelf Research, 17(6)717-721 (1997)

6 ) J. Song et al.: Novel use of soil moisture samples for studies on anaerobic ammonium fluxes across lake sedimentwater interfaces, Chemosphere, 50(6), 711
-715 (2003)

7 ) Frank M. Wilhelm et al.: A sediment core sectioning method to minimize the postsampling redistribution of organisms, Aquat. Sci., 59, 34-38 (1997)

(Submitted 2003. 3. 7)

(Accepted 2003. 4. 15) 